\title{
“SPIN-OFF" ACADÊMICO: CRIANDO RIQUEZAS A PARTIR DE CONHECIMENTO E PESQUISA
}

\author{
Maria H. Araújo e Rochel M. Lago* \\ Departamento de Química, ICEx, Universidade Federal de Minas Gerais, CP 702, 31270-901 Belo Horizonte - MG \\ Luiz C. A. Oliveira \\ Departamento de Química, Universidade Federal de Lavras, 372000-000 Lavras - MG \\ Paulo R. M. Cabral \\ Instituto Inovação, Rua Cláudio Manuel, 237, 31140-100 Belo Horizonte - MG \\ Lin Chih Cheng \\ Departamento de Engenharia de Produção Universidade Federal de Minas Gerais, 31270-901 Belo Horizonte - MG \\ Cândido Borges e Louis Jacques Filion \\ HEC, 3000 Côte Sainte-Catherine, Montréal, Quebec, H3T 2A7, Canadá
}

\begin{abstract}
ACADEMIC SPIN-OFF: CREATING WEALTH FROM KNWOLEDGE AND RESEARCH Technology companies created from University research are known as "Academic Spin-Off" (ASO). These innovative companies play an important role for the technological, economical and social development of a country. This work discusses some aspects of ASO companies and their importance to Universities. It is also presented a fictitious history of Prof. João, a chemical researcher who will create an ASO company from his academic research work illustrating the basic steps involved in this process.
\end{abstract}

Keywords: Academic Spin-Off; knowledge capitalization; entrepreneurship.

\section{INTRODUÇÃO}

\begin{abstract}
"Prof. João era um verdadeiro especialista na área de carvões ativados. Depois de seu curso de química realizou o mestrado, doutorado e pós-doutorado, trabalhando com carvões. João tinha muitas publicações científicas nacionais e internacionais, o que o tornava conhecido e respeitado pela comunidade acadêmica na área de carvão. Com seu conhecimento João era capaz de preparar carvões, caracterizá-los e utilizar reações químicas para modificá-los, de forma a produzir materiais muito especiais com propriedades únicas. O que mais encantava João nos carvões eram sua complexidade e, especialmente, sua enorme variedade de aplicações em diferentes processos industriais. Das poucas vezes que foi convidado para prestar consultoria para indústria João se realizou, não pelo dinheiro, mas pelo prazer de ver seu conhecimento utilizado de forma tão direta. Dividindo seu tempo entre aulas, trabalhos burocráticos, comissões, orientações, submissão de projetos e redação de artigos científicos, João realizava seu trabalho com muita dedicação. Não tardou até que, em um congresso, João encontrou um profissional do setor privado que lhe falou de algumas necessidades para tratamento de efluentes industriais e da falta de expertise nesta área. Nesta ocasião João se dera conta de quão preciosa era sua experiência e do potencial de aplicação de vários dos carvões que ele estava desenvolvendo para remoção de contaminantes de efluentes industriais. No meio da multidão de participantes do congresso e do ruído ininterrupto de "conversas químicas", João sentou-se em uma poltrona em um canto do salão do hotel e sonhou acordado: seus carvões sendo utilizados por indústrias e sua pesquisa se transformando em tecnologia. João sonhou mais alto: quem sabe uma empresa que, em colaboração com a Universidade, pudesse desenvolver novos materiais, pudesse gerar empregos, contratar químicos doutores, mestres e técnicos. João percebeu que este era
\end{abstract}

*e-mail: rochel@ufmg.br um sonho latente que estivera com ele durante muito tempo. E por que não? Perguntou-se João."

Esta é a história do Prof. João, um pesquisador fictício na área de Química que, depois de vários anos trabalhando em uma Universidade, acumulando grande experiência e desenvolvendo vários materiais com potencial de aplicação industrial, iria realizar um sonho latente de abrir uma empresa de base tecnológica, conhecida como "Spin-Off” Acadêmico (SOA).

\section{O QUE É UMA EMPRESA “SPIN-OFF” ACADÊMICO?}

Segundo a definição de Scott Shane um "spin-off" acadêmico (SOA) é uma empresa criada para explorar uma propriedade intelectual gerada a partir de um trabalho de pesquisa desenvolvido em uma instituição acadêmica ${ }^{1}$. Embora várias definições para SOA possam ser encontradas na literatura técnica ${ }^{2,3}$, algumas características importantes são: empresas que se originam em Universidades; empresas que irão explorar inovações tecnológicas, patentes e, também, o conhecimento acumulado por indivíduos durante atividades acadêmicas; empresas que são independentes das Universidade mãe e que têm fins lucrativos; empresas fundadas por pelo menos um membro da Universidade (professor, estudante ou funcionário). Alguns autores não fazem este tipo de restrição, podendo um "spin-off" ser fundado por pessoas sem qualquer relação com a Universidade 4 . No entanto, empresas que são criadas por funcionários ou ex-funcionários de instituições acadêmicas, mas que não comercializam o conhecimento ou a propriedade intelectual gerada nestas instituições, não são consideradas um "spin-off" acadêmico. SOA tem sido utilizado não só para denominar a empresa criada, como também o processo de criação desta empresa.

\section{"SPIN-OFF" ACADÊMICOS, EMPREENDEDORISMO E DESENVOLVIMENTO}

Empreendedorismo é o motor e o combustível da inovação. Não existem dúvidas, atualmente, de que o empreendedorismo, a inova- 
ção tecnológica e a comercialização de pesquisa são fenômenos intrinsecamente ligados e vitais para criação e manutenção da riqueza de um país ${ }^{5}$. Pesquisadores de Universidades, sejam professores ou alunos de pós-graduação, são atores únicos no processo de inovação pelo conhecimento tácito tecnológico ("know how") acumulado que possuem. Por isso, têm grande potencial para criarem produtos ou processos inovadores que são de grande importância para os desenvolvimentos tecnológico, econômico e social de um país.

Os "Spin-off" popularizaram-se com o surgimento do Vale do Silício e da Rota 128 nos em tornos de universidades de prestígio, como Standford e MIT. Desta forma, os SOAs têm sido parte da realidade de universidades americanas por décadas. Por outro lado, o fenômeno de SOA na Europa e especialmente no Brasil está ainda na infância. Embora os primeiros SOAs tenham aparecido na Europa na década de 70, muitas autoridades acadêmicas foram indiferentes ou mesmo contra o seu desenvolvimento ${ }^{2,6}$.

Assim, para a criação de SOA, além dos pesquisadores e idéias de produtos ou processos, é fundamental uma cultura empreendedora na Universidade que dê suporte à iniciativa do pesquisador empreendedor. A comunidade acadêmica deve se conscientizar de que o empreendedorismo tecnológico e o processo de capitalização do conhecimento, via criação de empresas de base tecnológica a partir de resultados de pesquisa, são alternativas muito positivas para a Universidade, a cidade, o estado e o país.

"Nos meses seguintes, o sonho de João foi ganhando força e mais forma. João sentia-se muito empolgado, com muita energia e revigorado pelas novas idéias e perspectivas. Afinal, sonhar faz bem. João tinha forte capacidade analítica, misturada com criatividade e um sonhar que o tornavam um visionário, uma pessoa à frente de seu tempo. João foi capaz de transformar seu sonho em visão. Projetou no futuro seus carvões nas indústrias e até uma empresa para desenvolvê-los. João sabia que isso seria completamente novo para ele e um grande desafio. Precisaria entender o setor industrial/comercial em que iria entrar e teria que investir bastante de seu tempo buscando as pessoas de diferentes áreas para estabelecer uma rede de contatos ("network") para apoiá-lo em seu sonho. Mas João se conhecia bem e sabia que tinha energia e liderança para isso. João decidiu então compartilhar o sonho e a visão com seus colegas e com seus estudantes. João percebeu que seus estudantes de IC foram os mais abertos às novas idéias e os que mais se empolgaram com sua visão de empresa tecnológica. Seus estudantes de pós-graduação pareciam demasiados focados em suas dissertações e teses para enxergarem fora da Universidade. Parecia que quanto mais se especializavam, mais restrito ficava o universo em que poderiam atuar. Nem sequer imaginavam que a criação de empresa poderia ser uma alternativa profissional. Afinal, eles foram educados para serem empregados. Por outro lado, Pedro, um engenheiro químico que fazia seu doutorado desenvolvendo parte do trabalho com os carvões, entusiasmou-se imediatamente com a idéia e seria o companheiro de João nesta empreitada. No entanto, a maior surpresa de João foi com a reação de muitos de seus colegas que não acreditavam em seu sonho, que se opunham ao envolvimento de pesquisadores com qualquer atividade fora da Universidade e achavam pouco ético utilizar a Universidade para criação de empresas. Afinal o que a Universidade iria ganhar com isso???"

\section{O QUE AS UNIVERSIDADES E A SOCIEDADE GANHAM COM A CRIAÇÃO DE EMPRESAS "SPIN-OFF"?}

A criação de uma empresa SOA vai ocorrer como resultado de um processo que tem a Universidade como base (Esquema 1). Sem a Universidade, com toda infra-estrutura e recursos, a criação deste tipo de empresa não seria possível. Assim, mecanismos para garantir um retorno das riquezas geradas com o processo de criação de SOA ou licenciamento de tecnologias para as Universidades são de grande importância.

Nas Universidades são atores fundamentais os pesquisadores e estudantes, que executam as duas funções clássicas: a educação/formação de recursos humanos $(\mathrm{RH})$ e o desenvolvimento da ciência e tecnologia (C\&T). A partir destes atores são desenvolvidas tecnologias e criadas empresas. Com a criação de empresas de base tecnológica ou licenciamento de patentes, as Universidades têm retorno financeiro direto na forma de royalties pagos pelas licenças das patentes; investimentos em $\mathrm{P} \& \mathrm{D}$ para desenvolvimento dos produtos/processos e bolsas para estudantes envolvidos nos projetos, etc. Além do retorno financeiro, as Universidades têm também um retorno intangível na forma de prestígio junto à sociedade e às agências de fomento, que têm valorizado fortemente este tipo de iniciativa nos últimos anos. A sociedade também se beneficia diretamente com a criação destas empresas, através da geração de divisas, empregos e tecnologias que levam ao desenvolvimento tecnológico, econômico e social.

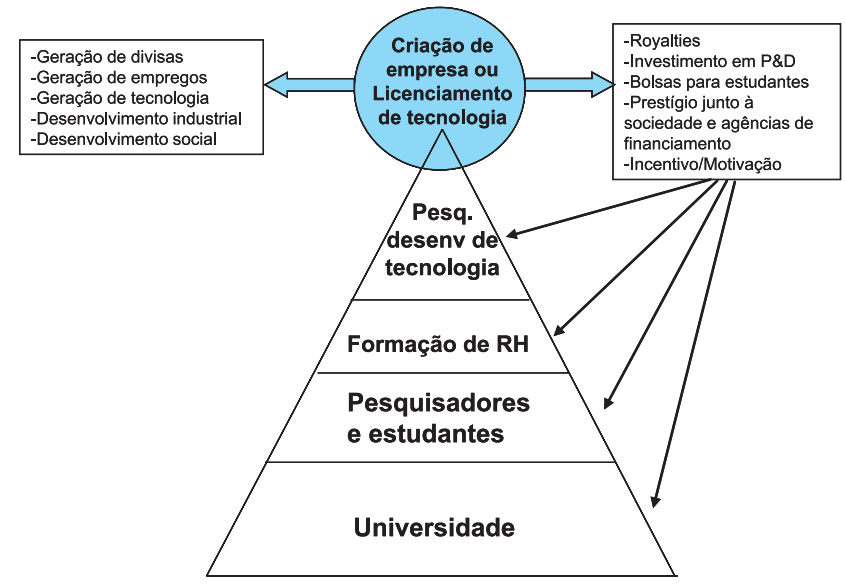

Esquema 1

Estes novos elementos que estão sendo inseridos na realidade da Universidade, tais como proteção intelectual, licenciamento de tecnologias e criação de SOAs, fazem parte de um processo chamado "capitalização do conhecimento", que tem causado uma "segunda revolução" na Universidade. Nesta revolução, além do ensino e da pesquisa, o desenvolvimento social e econômico é incorporado como parte da missão da Universidade, que tem sido chamada de "Universidade Empreendedora" .

\section{A importância de empresas "spin-off"}

As empresas SOAs têm um grande impacto, especialmente no desenvolvimento econômico local. Algumas razões para isso são:

- normalmente geram alto valor econômico, manufaturando produtos inovadores de alto valor agregado, satisfazendo necessidades e desejos de clientes específicos e diferenciados;

- geram empregos, especialmente para a população com maior grau de instrução;

- induzem o investimento no desenvolvimento de pesquisa, favorecendo o surgimento de novas tecnologias;

- têm impacto econômico fortemente localizado e acabam tendo um efeito importante na economia local.

Alguns destes tópicos serão discutidos mais detalhadamente em seguida. 
Empresas "spin-off” geram significante valor econômico

As empresas SOAs podem ter impactos econômicos diretos, indiretos e, intangíveis. Infelizmente no Brasil ainda não existem dados concretos sobre os impactos de empresas SOAs.

\section{Impactos econômicos diretos de SOAs acadêmicas}

Pesquisas estimam que empresas SOAs de universidades americanas têm tido um impacto financeiro direto relativamente grande na economia. Entre 1980 e 1999, essas empresas SOAs geraram US\$ 33.5 bilhões em valor econômico; em média, aproximadamente US\$ 10 milhões por empresa ${ }^{8}$.

\section{Impactos econômicos indiretos de SOAs}

Alguns trabalhos de pesquisa feitos em diferentes regiões do mundo sugerem que empresas SOAs têm um forte impacto econômico indireto, que em alguns casos pode ser maior que o impacto direto. Alguns exemplos notáveis são:

- a infraestrutura desenvolvida para criação da Route 128 (uma região em Boston que congrega grande número de empresas de alta tecnologia, especialmente na área de biotecnologia) tem sua origem em empresas de alta tecnologia onde $72 \%$, na década de 90, eram criadas a partir de tecnologias desenvolvidas nos laboratórios do MIT ("Massachussets Institute of Technology") $)^{9}$. Estudos na França entre 1987-1997 estimam que $40 \%$ das empresas criadas em alta tecnologia foram SOAs, mostrando a dependência do setor de alta tecnologia dos trabalhos desenvolvidos nas Universidades ${ }^{10}$. Em Cambridge (Inglaterra) em 1985, 17\% das empresas de tecnologias eram originárias de Universidades ${ }^{11}$, enquanto em Gotemburgo (Suécia) $5 \%$ das companhias de alta tecnologia saíram diretamente das Universidades ${ }^{12}$.

\section{Impactos econômicos intangiveis}

Embora estes impactos sejam difíceis de serem mensurados e mesmo discutidos podem ter uma grande importância, dependendo do contexto. Novamente no exemplo da Suécia, empresas SOAs levaram a uma diversificação econômica da área, tornando a economia menos dependente de um só tipo de indústria e, portanto, aumentando a estabilidade econômica.

Empresas "Spin-off" acadêmicos promovem o desenvolvimento econômico local

Empresas do tipo SOA têm normalmente um significativo impacto na economia local. Alguns destes impactos são os SOAs que transformam tecnologias desenvolvidas nas universidades em oportunidades de negócios e, todas as atividades econômicas de uma empresa SOA, como contratação, consumo de materiais, produção, tendem a ser locais. Todos estes fatores têm um efeito multiplicador na economia local. Outro efeito é a tendência de companhias tecnológicas formarem "clusters", isto é, arranjos locais que envolvem grupos de empresas concentradas em uma mesma área. Um exemplo de arranjo de empresas originou-se com as companhias Chiron e Genentech, que levou à formação de um "cluster" de biotecnologia em São Francisco (EUA) ${ }^{13}$. Outro fator importante é que as empresas SOAs são estabelecidas normalmente próximas à Universidade de origem. Isto é devido a que os pesquisadores, que criaram as empresas, continuam com ambas atividades empreendedora e acadêmica; novas pesquisas e novos contratos sãos estabelecidos entre a empresa e a universidade que deu origem ao SOA ${ }^{14,15}$. Por outro lado, tecnologias licenciadas para firmas já estabelecidas tendem a formar empresas em locais distantes das universidades de origem. Por ex., no Canadá $98 \%$ e nos EUA $80 \%$ das empresas SOAs estão localizadas nas mesmas províncias/estados de suas universidades ${ }^{16}$. Por outro lado, $71 \%$ das tecnologias licenciadas são exploradas fora dos estados onde se localizam as universidades ${ }^{17}$. Outro fator interessante é que a formação de um "cluster" tende a atrair vários outros setores, como por ex., escritórios de capitalistas de risco que tendem a montar uma infra-estrutura para dar suporte à criação de novas empresas.

A concentração de SOAs no em torno de universidades pode dar origem também aos "Parques Tecnológicos", que são grandes empreendimentos imobiliários configurados para receberem empresas de tecnologia, e que oferecem, além de área para instalação de empresas, centros de convivência, hotéis , áreas da lazer e estruturas gerenciais.

\section{Empresas "spin-off" geram empregos}

SOAs são importantes economicamente, pois criam empregos, especialmente para a população com maior nível de formação. Alguns dados de número de empregos criados por SOAs são mostrados na Tabela 1 .

Muitas destas empresas SOAs mostraram uma taxa maior de criação de empregos quando comparadas com empresas "start-up" destes mesmos países. As empresas SOAs também criam mais empregos que o processo de licenciamento de tecnologia para empresas já estabelecidas. Dados do MIT sugerem que empresas SOAs criam aproximadamente o dobro de empregos, quando comparados a uma tecnologia licenciada para empresa já estabelecida ${ }^{19}$.

\section{Empresas "spin-off" acadêmicos induzem investimento em tecnologias desenvolvidas em universidades}

A criação de empresas SOAs promove o investimento do setor privado em universidades, com o propósito de desenvolver tecnologias. Este investimento ocorre de várias formas, tais como, as próprias empresas SOAs investem para desenvolvimento de seus produtos e outras empresas, observando o resultado obtido, ganham

Tabela 1. Empregos criados diretamente por SOA em diferentes países ${ }^{18}$

\begin{tabular}{lcccc}
\hline País/Local & Período & No de SOAs criados $^{\mathrm{a}}$ & $\mathrm{N}^{\circ}$ de Empregos & $\mathrm{N}^{\mathrm{o}}$ empregos por SOA \\
\hline EUA & $1980-1999$ & 3253 & $280 \mathrm{mil}$ & $\mathrm{ca} .83$ \\
UK & - & - & - & $\mathrm{ca} .44$ \\
Suécia, Univ. Linkoping & Até 1992 & 53 & 445 & $\mathrm{ca} .12$ \\
Holanda, Univ. Twente & $1984-1992$ & 92 & 250 & $\mathrm{ca} .5$ \\
Bélgica, Univ. Liege & $1986-1994$ & 25 & 180 & $\mathrm{ca} .10$ \\
Irlanda, Queens Univ. & $1984-1995$ & 17 & $\mathrm{ca} .11$ \\
\hline
\end{tabular}

${ }^{a}$ SOAs criados a partir de propriedade intelectual (PI). Existem SOA que podem ser criados sem PI, por ex., empresas de software e de consultoria. 
mais confiança para investir. Dados obtidos do MIT e da Universidade de Columbia sugerem que os investimentos nas Universidades obtidos de empresas SOAs são 20 a 40 vezes maiores, quando comparados com os valores obtidos com os royalties do licenciamento de patentes.

Empresas "spin-off” acadêmicos aumentam a comercialização de tecnologias geradas na Universidade

As SOAs promovem a comercialização de tecnologias desenvolvidas que ficaram sub-exploradas. Este efeito se dá através de duas vias: SOA é um mecanismo de comercialização de tecnologias que seriam muito arriscadas para firmas já estabelecidas explorarem e, motiva o envolvimento do inventor com os estágios posteriores de desenvolvimento da tecnologia, o que é essencial quando as tecnologias são baseadas em conhecimento tácito/técnico.

SOA, em alguns casos, é a única forma de comercializar tecnologias desenvolvidas em Universidades, visto que empresas já estabelecidas, em geral não estão dispostas a investirem em tecnologias em um estágio tão prematuro de desenvolvimento, o qual apresenta um elevado risco ${ }^{20}$.

Empresas "spin-off" acadêmicos encorajam o envolvimento de pesquisadores na comercialização de tecnologias

As empresas SOAs são um meio efetivo para envolver pesquisadores na comercialização de tecnologias, uma condição normalmente necessária para a tecnologia chegar até o mercado. As invenções normalmente necessitam de desenvolvimento posterior, onde a participação do pesquisador é muito importante. No caso de empresas SOAs, comparado ao licenciamento, o envolvimento do pesquisador tende a ser facilitado pois, os pesquisadores têm a percepção que empresas iniciantes são lugares mais interessantes para trabalhar, em função de oferecerem ambiente mais flexível, criativo e desafiador, e tendem a ter pessoas mais empreendedoras e dinâmicas ${ }^{21}$; empresas iniciantes, além da parte comercial, focam também o desenvolvimento da tecnologia e os pesquisadores tendem a apreciar mais o lado tecnológico que outros aspectos do lado comercial do empreendimento; os pesquisadores têm a percepção que podem contribuir mais para o desenvolvimento de um negócio no estágio inicial que em um licenciamento para uma grande empresa e, a participação direta na empresa é em si um grande incentivo para os pesquisadores.

Empresas "spin-off" acadêmicos ajudam a Universidade com sua missão

As SOAs são importantes para a Universidade pois contribuem na sua missão que é ensino e pesquisa. Pesquisas demonstram que as SOAs podem contribuir de três diferentes maneiras:

- as SOAs são uma motivação adicional para a pesquisa. A produtividade científica está diretamente correlacionada com as atividades empreendedoras da instituição ${ }^{22}$. Além disso, SOA aumenta a disponibilidade de fundos para pesquisa. Atualmente no Brasil, as Agências de Financiamento de Pesquisa têm consistentemente incentivado o envolvimento de pesquisa com o setor privado ou mesmo com a criação de empresas. Outras formas de ajuda são bolsas de estudos para alunos de graduação, de mestrado e de doutorado e, também, na forma de doações pelas empresas, por ex., equipamentos. Além disso, empresa SOA criada em conjunto com laboratório de pesquisa oferece outras possibilidades de obter financiamentos;

- SOAs atraem pesquisadores e estudantes talentosos. Ativida- des empreendedoras em uma universidade são importantes para atrair pesquisadores e estudantes talentosos, pois permitem aos membros realizarem seus sonhos e aspirações e oferecem uma rota alternativa de ascensão econômica e,

- SOAs ajudam na educação e treinamento de estudantes. O envolvimento da universidade com empresas SO é uma maneira efetiva de educar/treinar estudantes em suas áreas com um componente empreendedor que tem sido cada vez mais um aspecto de grande importância na formação de profissionais, seja para o trabalho como empregado ou mesmo para a geração de novas empresas.

\section{COMO FUNCIONA NA PRÁTICA A CRIAÇÃO DE UM "SPIN-OFF" ACADÊMICO?}

“João estava certo que sua pesquisa e sua Universidade só ganhariam com a criação de uma empresa. João queria realizar seu sonho. Mas por onde começar? Como transformar sua visão em ação? Como saber se os carvões que havia desenvolvido eram realmente interessantes comercialmente? Será que iriam ter aplicação na indústria? Será que alguém os compraria? Qual dos carvões que ele havia desenvolvido seria o mais interessante? Se criasse uma empresa, o que ela faria? Fabricaria carvão, modificaria, só venderia ou daria consultoria e assistência técnica para indústrias? Nem sequer a atividade principal da futura empresa de João estava definida! Como preparar alguns quilos destes carvões para testes em indústrias? Afinal, ele preparava até então somente alguns gramas de carvão na bancada! Como organizar uma empresa? Onde conseguir dinheiro para montar uma empresa? João percebeu que, como pesquisador, dominava toda a química dos processos, mas a parte da viabilidade técnica, desenvolvimento de produto e viabilidade econômica era completamente nova para ele! João com freqüência se sentia inseguro e se perguntava constantemente se conseguiria levar adiante seu sonho e se tinha realmente perfil de empreendedor. Ele sabia que existiam riscos nessa aventura, mas riscos que poderia correr. Com seu otimismo e dinamismo, sua perseverança e criatividade João sabia que poderia realizar seu sonho. Tinha capacidade de organizar, definir metas, montar equipes e compartilhar o entusiasmo. Conseguiria encontrar todos os recursos necessários e, embora não conhecesse exatamente como fazer, João tinha certeza que só aprenderia fazendo. Sem medo de errar aprenderia muito com seus erros!...”

A criação de uma empresa é um desafio monumental para um pesquisador acadêmico. Um momento crucial no processo de criação de um SOA é a decisão do pesquisador de empreender. O pesquisador tem que estar consciente que o processo de criação de um SOA é completamente diferente de seu universo, que demandará trabalho intenso e desenvolvimento de outras habilidades. Assim, a decisão de empreender deve passar por um processo profundo de reflexão, acompanhado de muita conversa, pesquisa e leitura. Para o leitor mais interessado especificamente neste ponto indicamos as sugestões de leitura e referências sobre a "Teoria Visionária" no processo empreendedor de Filion ${ }^{23}$.

Existem vários modelos que discutem este processo, dividindo em fases ou etapas a criação de empresas SOAs. Embora nos diferentes modelos propostos a divisão varie um pouco, pode-se considerar quatro fases principais:

- Estágio 1: identificação de idéias/oportunidades com potencial de negócio e sua proteção;

- Estágio 2: avaliação da viabilidade técnica e econômica e do 
potencial mercadológico da idéia;

- Estágio 3: criação da empresa e,

- Estágio 4: consolidação da empresa e criação de valor econômico.

As características e os atores principais de cada fase serão discutidos a seguir:

“...João soube que em sua Universidade havia sido criado recentemente um Escritório de Transferência de Tecnologia (ETT) e, embora não soubesse exatamente o que este órgão fazia, foi visitálo. Descobriu que este escritório seria muito importante para ele. No primeiro encontro João conversou com Paulo, coordenador do ETT, e Juliana a advogada, e iniciaram uma avaliação de qual seria o potencial de negócio para os carvões desenvolvidos. Se caso os carvões de João fossem realmente interessantes, a primeira providência seria obter uma patente. Deste encontro, João saiu com uma lista de pontos para pesquisar e de alguns bancos de patentes para realizar uma busca prévia e descobrir se seus carvões já haviam sido patenteados antes. Após três semanas de trabalho intenso com ajuda de seu aluno de doutorado Pedro, João tinha agora uma idéia um pouco melhor do potencial de seus carvões $e$, ainda de forma muito preliminar, tudo indicava que tinha nas mãos uma oportunidade de negócio interessante. A revisão nos bancos de patentes mostrou que não havia nada similar aos seus carvões. João juntamente com seu aluno Pedro, auxiliados por Juliana, trabalharam no preparo da patente. Muito diferente dos artigos científicos, o preparo do texto da patente foi um bom aprendizado para João e Pedro. Pedro estava muito feliz em ser o autor de uma patente, mas não sabia exatamente porque patentear era importante. João explicou que a patente garantia a autoria da descoberta ou invenção dos carvões e que dava o direito de explorar esta invenção comercialmente. Explorar comercialmente? Perguntou Pedro. A patente poderia ser licenciada para uma indústria. Em troca, a indústria pagaria uma taxa em função daquilo que faturasse com a invenção. Esta taxa é chamada de royalties. Os royalties recebidos normalmente são divididos em três partes, uma para a Universidade, outra para o ETT e outra para os inventores. João e Pedro estavam muito contentes e entusiasmados com o novo mundo que se abria diante eles. João então comentou com Pedro a outra possibilidade, que era a criação de uma empresa para explorar a patente. Esta possibilidade fazia os olhos de João e Pedro brilharem..."

A identificação de uma idéia como potencial de negócio no Estágio 1 depende fortemente do pesquisador, de sua abertura para a exploração dos resultados de pesquisa e de sua capacidade em perceber oportunidades de negócio. A idéia de negócio vai surgir de um trabalho de pesquisa que tem potencial para gerar um produto ou processo inovador. Avaliar o potencial de uma invenção não é uma tarefa simples e pode demandar habilidades e conhecimentos que normalmente os pesquisadores não possuem. Nesta fase é interessante a participação de Escritórios de Transferência de Tecnologia (ver por ex., CTIT Coordenadoria de Transferência e Inovação Tecnológica, http://www.ufmg.br/prpq/ctit.htm), incubadoras (por ex., www.anprotec.com.br e www.inova.ufmg.br) e centros de empreendedorismo (por ex., http://www.empreende.eng.ufmg.br).

“...João e Pedro sentiram grande dificuldade para avaliar se os carvões que desenvolveram realmente eram uma boa oportunidade de negócio. Muitas perguntas ainda precisavam de respostas mais detalhadas, como por ex., quais seriam os usos e qual o mercado em potencial para os carvões, quais os produtos concorrentes já existentes, como seriam preparados estes carvões em escala industrial e qual seria o custo. João e Pedro foram então procurar o Centro de Empreendedorismo (CE), que Paulo do ETT sugerira. No CE encontraram Alexandre, que lhes falou pela primeira vez do EVTE - Estudo de Viabilidade Técnica e Econômica, que deveria responder muitas das questões que ocupavam suas mentes. Através de um projeto do SEBRAE João conseguiu dinheiro para realização do EVTE, que serviu para fazer uma pesquisa de mercado e foi utilizado para desenvolver uma parte do trabalho no laboratório. A pesquisa de mercado foi realizada por alunos de uma Empresa Júnior (EJ) da Universidade. Sob orientação de Alexandre do CE e com ajuda de João e Pedro, os alunos da EJ de uma forma muito profissional fizeram um trabalho excelente, produzindo um relatório detalhado de todas as empresas que poderiam utilizar os carvões, qual era o mercado potencial, quais eram os concorrentes no Brasil e internacionais, dos preços cobrados, etc. Além disso, este EVTE mostrou várias outras necessidades do mercado que os carvões de João poderiam satisfazer, e outras onde não havia solução e que João poderia desenvolver. Este EVTE acabou por influenciar diretamente os rumos da pesquisa de João."

No Estágio 2, alguns aspectos técnicos e econômicos da tecnologia desenvolvida devem ser avaliados. A melhor ferramenta para esta avaliação é o EVTE, estudo de viabilidade técnica e econômica. Normalmente pesquisadores não têm experiência com EVTE e necessitam de ajuda para sua realização. O SEBRAE, através de seu programa SEBRAETEC, e a FINEP têm financiamentos

Quadro 1. Características do Estágio 1 no processo de criação de uma empresa "spin-off”: identificação de oportunidades de negócio e proteção da idéia

\begin{tabular}{lll}
\hline Estágio & Características & Atores \\
\hline Estágio 1. Identificação de idéias com & Neste estágio deve haver uma identificação & - Professores pesquisadores e alunos \\
potencial de negócio e proteção. & das idéias e uma avaliação inicial de seu & - Escritório de transferência de tecnologia \\
Nasce no meio acadêmico a idéia do & potencial tecnológico e econômico. Esta & (ETT), incubadoras, centros de \\
negócio com algumas indicações de & avaliação é ainda muito aproximada & empreendedorismo de Universidades podem \\
seu potencial tecnológico e econômico. & devido à necessidade de um maior & auxiliar nesta avaliação inicial. Universidades \\
& desenvolvimento tecnológico e, em alguns & e FAPs podem auxiliar no preparo e depósito \\
& casos, devido ao alto grau inovador do & de patentes
\end{tabular}

produto que ainda não tem um mercado específico.

No caso da idéia mostrar um bom potencial deve ocorrer sua proteção, por ex., na forma de patente 
com o objetivo de realizar EVTEs (www.sebrae.com.br). Para o leitor interessado, a ref. 24 apresenta uma análise bastante detalhada do processo de EVTE-SEBRAETEC, com pesquisadores de diferentes áreas da Universidade Federal de Minas Gerais. Outra ferramenta que é sugerida especialmente para empresas de base tecnológica é a plano tecnológico, que contempla o desenvolvimento do produto ou serviço e explicita o caminho da tecnologia até o mercado ${ }^{25}$. Para o leitor interessado em mais detalhes, no desenvolvimento deste plano tecnológico são sugeridas algumas metodologias já bem definidas na literatura, por ex., "Technology Roadmapping"26 e "Technology Stage-Gate"27.

“...João foi interrompido no meio de sua aula experimental por um telefonema de Paulo, do ETT. Uma indústria grande estava interessada na patente de João e queria uma reunião para discutir o processo de licença. João e Pedro quase explodiam de tanta alegria. Afinal, no Brasil, licenciar uma patente para a indústria ainda é um feito incomum e deve ser comemorado! Os encontros com a indústria se iniciaram. João e Pedro, ao participarem das reuniões, se deram conta de que eles e os representantes da indústria tinham formas diferente de pensar. Falavam "idiomas" diferentes. Como era interessante aprender o novo idioma!

Neste estágio, os pesquisadores podem se deparar com o dilema entre licenciar a tecnologia para uma indústria já estabelecida ou montar uma empresa para explorar a tecnologia. No caso de uma indústria se interessar pela patente o pesquisador, em conjunto com o ETT, deverá decidir se a licença da patente para esta indústria é algo interessante tanto para o pesquisador como para a Universidade e se a licença será exclusiva ou não, isso é, se a patente será licenciada somente para uma indústria ou para várias indústrias. Os dados obtidos no EVTE podem ser muito valiosos para analisar a oportunidade e os riscos envolvidos na comercialização da tecnologia, o que será muito importante para decidir entre a licença e a criação de um SOA.

“...Apesar da complexidade de negociação, as chances de licenciar a patente para a indústria eram boas. Neste período, João começou a se questionar sobre a direção que o seu sonho e sua visão estavam tomando. Apesar de estar muito contente com a situação, João ainda se encantava com a idéia de explorar suas invenções através da criação de uma empresa. Tinha ainda muitas dúvidas e inseguranças, pois não sabia nada sobre empresas e sobre os procedimentos legais e burocráticos. Teria que pagar impostos? E se a empresa falisse, quais seriam suas responsabilidades? Muitas coisas ainda estavam por responder, mas João estava certo que encontraria facilmente as respostas para todas estas perguntas e que isso não deveria matar seu sonho. Em uma longa conversa com Paulo do ETT, João tentou mostrar que seus carvões eram uma oportunidade comercialmente muito interessante. Argumentou que, embora a criação de uma empresa implique em um risco maior que a licença, os benefícios potenciais para a Universidade e para a região seriam muito maiores. No entanto, a criação de uma empresa depende fortemente do perfil do pesquisador e de seu desejo de empreender. $O$ caminho não seria fácil, mas João e seu aluno Pedro estavam dispostos. Eles sabiam que não tinham todos os conhecimentos para criar uma empresa e precisariam de muita ajuda."

Os pesquisadores podem decidir que a melhor forma de explorar a invenção é criar uma empresa de base tecnológica. Esta decisão é bastante séria e vai depender de muitos fatores mas, principalmente, do perfil dos pesquisadores e suas competências. Além disso, a criação de "spin-off" é uma atividade que, sem dúvida, oferece um alto risco. Alguns destes riscos são: risco tecnológico associado ao desenvolvimento de uma tecnologia ou produto completamente novo; risco associado às incertezas do mercado frente à comercialização de uma nova tecnologia ou produto inovador e, riscos organizacionais e financeiros associados a empresas nascentes (conhecidas como empresas "start-up"). Assim, as pessoas envolvidas na criação de uma empresa devem estar conscientes destes riscos e tomar todas as medidas possíveis para minimizá-los.

“...João então começou a transformar sua visão de empresa em realidade. Necessitava montar uma unidade piloto e produzir seus carvões em maior quantidade, precisava realizar análises de mercado mais detalhadas e talvez até contratar pessoas, técnicos, químicos com dedicação integral para tirar a empresa do papel. Onde conseguiria dinheiro para isso? Foi buscar pessoas que são conhecidas como investidores anjos ("Angel investors") que oferecem dinheiro conhecido como "capital semente" nesta fase onde a empresa está começando a se organizar. Em troca deste capital semente estes investidores ficam donos de uma parte da empresa. Para o investidor esta é a fase de maior risco da empresa, pois ainda existe somente uma idéia de oportunidade mas nenhuma garantia bem definida. João passou vários meses buscando um investidor anjo e percebeu que no Brasil este tipo de investidor ainda é raro. Felizmente, João foi encontrar no SEBRAE e na FINEP uma possibilidade de financiamento, conseguindo a aprovação de

Quadro 2. Características e atores principais do Estágio 2 no processo de criação de uma empresa "spin-off”: avaliação da viabilidade técnica e econômica do processo

\begin{tabular}{lll}
\hline Estágio & Características & Atores \\
\hline Estágio 2. Avaliação da viabilidade & Neste estágio pode ser definida a forma & - Pesquisador \\
técnica e econômica e do potencial da & de explorar a idéia: venda, licença ou & - ETT, incubadoras e centros de \\
idéia. A idéia é agora avaliada quanto à & criação de uma empresa "spin-off". & empreendedorismo e mesmo empresas \\
sua viabilidade técnica e econômica. & -No caso de criação de "spin-off": & juniores de Universidades \\
Este estágio também tem sido chamado & desenvolvimento tecnológico (protótipo, & - SEBRAE e FINEP apóiam financeiramente \\
de pré-incubação & planta piloto) e desenvolvimento comercial & projetos EVTE e projetos para construção de \\
& (plano de negócios). Nesta fase é & protótipos e plantas piloto \\
& importante também uma análise das & \\
& exigências legais, ambientais, sanitárias, & \\
& etc. do produto/processo que se pretende & \\
& colocar no mercado. & \\
\hline
\end{tabular}


projeto para construção de unidades piloto, para tentar realizar as modificações de carvões ativados em escala maior. Com ajuda de seu aluno Pedro, que era engenheiro químico, desenvolveram uma mini-planta que permitia realizar o processo químico em escala maior. Com esta mini-planta foram capazes de perceber muitos pontos importantes para produção de uma planta industrial e muitas questões estratégicas de fornecimento de reagentes, estocagem, efluentes a serem tratados e conseguiram levantar dados para melhor análise econômica do processo. Produzindo os carvões em maior quantidade, João e Pedro começaram a ter contato preliminar com clientes potenciais. Este contato foi muito importante, pois João e Pedro puderam perceber que os critérios destes clientes para um bom produto eram muitas vezes bem diferentes daqueles que tinham imaginado e era fundamental entender melhor a real necessidade destas indústrias. Através destes contatos receberam várias sugestões importantes para desenvolvimento de seus produtos e até descobriram várias outras demandas dos clientes, que eram oportunidades futuras para a empresa."

Uma vez que os pesquisadores decidem montar uma empresa para explorar a invenção torna-se necessário encontrar capital, infraestrutura e pessoal para tal. Capital semente é a alternativa nesta fase da empresa. Nos EUA, no Canadá e na Europa este tipo de capital é relativamente comum, no entanto, no Brasil são ainda poucas as possibilidades. Algumas destas alternativas são o projeto SEBRAETEC Inovação Tecnológica, que oferece capital para montagem de protótipos e plantas piloto; o fundo Inovar Semente, criado pela Financiadora de Estudos e Projetos (Finep) e, bolsas do tipo DTI (Desenvolvimento Tecnológico Industrial).

“...Com a mini-planta João e Pedro agora eram capazes de produzir alguns quilos de carvões e oferecer para diferentes indústrias, para realização de testes preliminares. A cada passo sentiam que se aproximavam do mundo fora da Universidade - o mercado, a indústria! Foi nesta fase que João encontrou o Sr. Gustavo, um engenheiro aposentado que trabalhou toda sua vida na indústria química, tanto na parte de engenharia como diretor comercial também. João e Pedro perceberam quão valioso Gustavo seria para a futura empresa. O Sr Gustavo tinha mais de 40 anos de indústria, conhecendo muito bem todo o setor onde João gostaria de atuar e tendo uma imensa rede de contatos ("network"). Gustavo seria certamente uma pessoa muito importante para o sucesso do empreendimento. Gustavo complementava toda a parte de gestão que João e Pedro tinham deficiências e foi, então, convidado para ser sócio da empresa e trabalharia em tempo integral dali em diante. Uma das lições que João e Pedro sempre se lembram do Gustavo é "Caros João e Pedro, no mercado, a avaliação dos produtos é totalmente diferente da que vocês pesquisadores fazem! O mercado preocupa-se muito com uma relação custo/benefício positiva. Defeitos, falhas, incertezas, podem ser aceitáveis se a relação custo/benefício, o risco, etc. forem considerados satisfatórios. Muitas vezes o produto não precisa ser perfeito. Precisa ser melhor que o concorrente! Pense em quantos produtos consumimos que são fracos! Que tem problemas...”. E João e Pedro pensavam - que interessante! A empresa estava nascendo. João e Pedro sentiram que estava na hora de procurarem uma incubadora."

$\mathrm{Na}$ fase de criação e operação da empresas, a participação de pessoas que tenham experiência administrativa e, preferencialmente, experiência no mercado/setor onde se pretende atuar e que possam trazer consigo toda a rede de contatos criada é certamente muito valiosa.

“...Após uma longa reunião sobre a empresa os sócios - João, Pedro e Gustavo - decidiram utilizar a incubadora da Universidade para criar a empresa. A incubadora oferece vantagens únicas às empresas incubadas, tais como espaço físico com toda a infra-estrutura primária necessária como telefone, fax, Internet por um custo bastante baixo. Se a empresa fosse montada em um espaço privado o custo seria muito maior. Além disso, na incubadora João e Pedro poderiam fazer alguns cursos sobre empreendedorismo, sobre questões financeiras, legais, marketing, etc. e teriam consultoria de especialistas disponíveis dentro da incubadora. Na incubadora as empresas recém-nascidas recebem um cuidado especial para que as chances de sucesso aumentem.

Para fazer parte da incubadora, João e Pedro tiveram que trabalhar em algo que era completamente novo para eles: o Plano de Negócios $(P N)$ - onde os sócios tinham que descrever o que era o negócio, qual o principal produto/serviço, quais os recursos humanos necessários para a nova empresa, qual era o mercado existente, seu tamanho e sua localização, qual seu potencial de crescimento, qual a estratégia de marketing mostrando como o produto seria vendido, como novos clientes seriam conquistados, os métodos de comercialização, os diferenciais do produto, o plano financeiro com fluxos de caixa e muitas outras projeções para os próximos cinco anos. Embora parecesse " futurologia" no princípio, João e Pedro perceberam que este plano de negócios seria fundamental para planejar a empresa, antecipar vários problemas e mesmo encontrar outras oportunidades de negócio. O plano negócio funcionava como um mapa."

Incubadoras universitárias são alternativas muito interessantes para empresas que estão nascendo, por todas as facilidades que oferecem e pela assistência nas áreas administrativa e gerencial que podem ser muito importantes para pesquisadores que não possuem experiência prévia com empresas.

“...Após um ano a empresa incubada se desenvolvia. A unidade piloto já produzia quantidades do carvão suficiente para realização de testes nas indústrias. O projeto de uma planta industrial já havia sido iniciado. Questões legais e ambientais estavam sendo discutidas. Através dos contatos de Gustavo, vários testes em indústrias estavam sendo realizados e várias companhias já demonstravam interesse nos produtos desenvolvidos.

João e os sócios já participavam de feiras comerciais e industriais apresentando o produto e fazendo contatos. Uma análise setorial muito mais detalhada havia sido feita. Além de Pedro, que dedicava parte do tempo para o desenvolvimento dos produtos, e Gustavo, que se dedicava integralmente, a empresa já pensava em contratar um técnico em química, um químico estagiário da Universidade e uma secretária. Já existiam também planos para contratar para o próximo ano um profissional na área de administração, que pudesse cuidar da parte de gestão financeira, vendas e marketing da empresa. A empresa estava crescendo. Os sócios agora sabiam que, em breve, a empresa deveria dar um salto. Sua estrutura organizacional deveria crescer bastante e as vendas de produtos deveriam ser priorizadas para gerar receita para a empresa. Logo a empresa sairia da incubadora e tornar-se-ia independente. Certamente a empresa necessitaria de capital para esta transição." 
Quadro 3. Características e atores principais do Estágio 3 do processo de criação de uma empresa "spin-off”: incubação

\begin{tabular}{lll}
\hline Estágio & Características & Atores \\
\hline Estágio 3.Criação da Empresa. & Com a oportunidade já bem definida, neste & -Pesquisador \\
Criação da empresa encontrando os & estágio ocorre a criação da empresa que & -Equipe administrativa/operacional \\
recursos humanos e financeiros. & entra em sua "infância organizacional” com & -Investidores (“Anjos”, capitalistas de risco) \\
Este estágio tem também sido chamado & o arranjo de: recursos materiais, como infra- & -Especialistas externos (mentores/ \\
de incubação. & estrutura para teste e desenvolvimento de & conselheiros) e rede de contatos \\
& produto; recursos financeiros e, talvez, & Agências governamentais (FAPs, FINEP, \\
& contratação de algumas pessoas para compor & CNPq) podem ser importantes para \\
& a parte administrativa/operacional. & financiamento \\
& Neste estágio a empresa normalmente não & \\
& tem qualquer receita e necessita de fundos & \\
& para sua existência. & \\
\hline
\end{tabular}

Após a fase de incubação, chega um momento crítico onde a empresa se encontra preparada para o mercado e deve iniciar sua transição para a adolescência. Esta transição implica em aumento no pessoal contratado pela empresa. Embora o desenvolvimento/ aperfeiçoamento tecnológico ainda aconteça, o foco passa a ser na venda e no mercado. A empresa deve começar a gerar um retorno financeiro a partir das vendas.

“...Os sócios da empresa preparavam um novo plano de negócios, agora muito mais detalhado. Precisavam deste PN para a apresentação da empresa a investidores para solicitar capital. João, Pedro e Gustavo estavam prestes a iniciar uma nova fase da empresa. Uma das possibilidades que consideravam era obter dinheiro de capitalistas de risco (Venture Capital), que são pessoas ou organizações que poderiam financiar um grande volume de dinheiro para a empresa. Em troca, uma parte da empresa passaria a pertencer aos capitalistas de risco. Normalmente, o capitalista de risco sendo parte da empresa pode colocar alguém diretamente na administração da empresa, que pode aportar conhecimento, experiência e sua rede de contatos também. Embora João e Pedro tivessem a sensação de que a empresa ficaria "menos" deles, pois o número de sócios aumentaria, isso não os incomodava porque sabiam que fazia parte do processo de crescimento da empresa. Além disso, os novos sócios capitalistas poderiam ensinar muito da parte empresarial a eles. Outras possibilidades eram financiamentos governamentais, por ex., das fundações de amparo à pesquisa, FINEP, etc. Enfim, existiam algumas possibilidades para obtenção de capital. O que o futuro reservava para essa nova empresa? Como bons empreendedores, João, Pedro e Gustavo já imaginavam várias possibilidades: a empresa crescendo e gerando lucro, contratando mais pessoas, desenvolvendo novos produtos, sua sede própria. Quem sabe uma outra empresa grande se interessaria por comprá-la? Quem sabe entrariam no mercado de ações com uma oferta pública?

E com relação ao Prof. João? Continuava acadêmico. De fato, sua produtividade científica havia aumentado neste período e, além das publicações, tinha agora as patentes. Pedro estava prestes a defender sua tese e tinha planos de se dedicar à empresa e fazer uma especialização na área de administração. Juntos sempre lembravam o início e todas as pedras que encontraram no caminho. E numa gostosa gargalhada recitavam Mark Twain "Dois loucos não sabiam que a coisa era impossível; então eles a fizeram."

\section{ALGUNS DILEMAS QUE SE ORIGINAM COM A CAPITALIZAÇÃO DO CONHECIMENTO E CRIAÇÃO DE EMPRESAS SOAS}

Para a comunidade acadêmica, explorar comercialmente as atividades de pesquisa requer uma grande mudança na forma de pensar e trabalhar. Nós acadêmicos sempre tivemos a ciência como um fim em si própria, onde a pesquisa científica tem como objetivo o aumento e a melhora do conhecimento, independente de qualquer aplicação prática ${ }^{28}$. Neste modelo, a pesquisa acadêmica é um bem público e a academia reconhece apenas duas formas básicas de explorar o conhecimento: na forma de publicações e de educação. De acordo com Ndonzuau e colaboradores ${ }^{29}$ a mudança da cultura acadêmica deve alterar três características fundamentais: o lema "publish or perish" (publique ou pereça), a relação ambígua dos pesquisadores com dinheiro e, a natureza desinteressada da pesquisa acadêmica.

A avaliação do desempenho de pesquisadores acadêmicos, no Brasil e no mundo, hoje é feita essencialmente por sua contribuição para o avanço da ciência. Esta avaliação é feita basicamente através de publicações em periódicos científicos. Desta estratégia

Quadro 4. Características e atores principais do Estágio 4: a consolidação de uma empresa "spin-off"

\begin{tabular}{lll}
\hline Estágio & Características & Atores \\
\hline Estágio 4. Consolidação da Empresa & Neste estágio a empresa é capaz de gerar: & Nesta fase o pesquisador pode ainda participar \\
e criação de valor econômico. & -riqueza, emprego, investimentos, etc. & no aprimoramento de produtos/processos. \\
Empresa consolidada que gera & -renovação econômica, dinamismo & $\begin{array}{l}\text { Mas os principais atores são a equipe } \\
\text { administrativa/operacional e o pessoal de } \\
\text { valor econômico }\end{array}$ \\
& empreendedor, constituição de centros & \\
& de excelência. & \\
& A empresa está em sua adolescência \\
& organizacional e necessita de profissionais \\
& da área de marketing, finanças, etc para \\
& impulsionar as vendas. \\
\hline
\end{tabular}


vem o lema "publish or perish" que significa, literalmente, publique ou pereça. Do ponto de vista econômico, esta estratégia tem uma forte influência no valor do conhecimento para a Universidade, visto que uma vez publicado, o conhecimento cai em domínio público e perde a proteção legal na forma de patente. As patentes são instrumentos muito importantes na valorização do conhecimento e na transferência legal deste conhecimento para o setor privado.

Pesquisadores acadêmicos consideram o dinheiro apenas como um meio para a realização de suas pesquisas. E este dinheiro tem vindo, no caso do Brasil, na sua maioria do poder público. No novo modelo tanto o desenvolvimento da ciência como desenvolvimento econômico devem se integrar (Esquema 2), onde o pesquisador assume um papel múltiplo de desenvolver pesquisa e ciência e criar riqueza e desenvolvimento social a partir de seu trabalho.

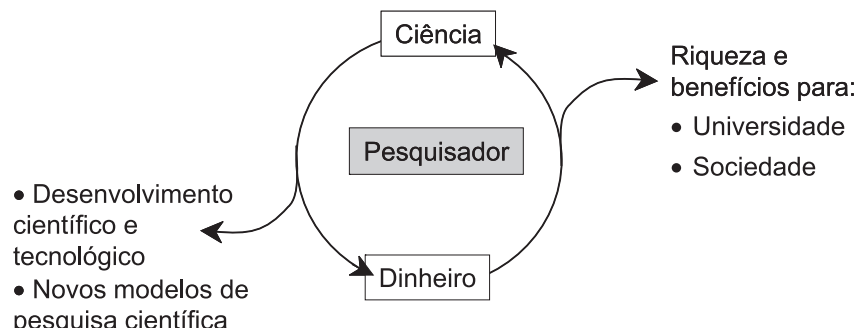

pesquisa científica

\section{Esquema 2}

Podemos citar como ex. o MIT, "Massachusetts Institute of Technology", que foi criado em 1864 como uma escola de ciência industrial com objetivo principal de desenvolvimento tecnológico e industrial (http://libraries.mit.edu/archives/mithistory/ founding.html). Embora sua origem tenha sido tecnológica, o MIT é hoje uma instituição que desenvolve uma importante parte da ciência básica no mundo, dando origem a 59 prêmios Nobel (24 professores, 20 ex-alunos e 15 pesquisadores) (http://web.mit.edu/ newsoffice/special/nobels.html). Por outro lado, um estudo do Banco de Boston de 1997 mostrou que o MIT produziu 4000 "spinoff" acadêmicos, empregando 1.1 milhão de pessoas com 232 milhões de dólares em negócios ${ }^{30}$.

A "natureza desinteressada" da pesquisa tem origem na tradição de supervalorizar a pesquisa fundamental. Esta tradição tende a menosprezar a pesquisa aplicada e os pesquisadores que "prostituem a ciência" por buscarem objetivos e metas outros que não o desenvolvimento da ciência exclusivamente. Atualmente, torna-se comum os pesquisadores assumirem a missão de "servir à sociedade", onde a capitalização do conhecimento e sua exploração comercial tornam-se possíveis. Vale enfatizar aqui que a pesquisa básica tem um enorme valor na Universidade e, sem dúvida, vai continuar a ter seu espaço.

\section{SUGESTÕES DE LEITURA}

Para os leitores interessados na área de empreendedorismo em geral são sugeridas as seguintes publicações:

- "Oficina do Empreendedor" de F. Dolabela; 6 a ed., Ed. de Cultura: São Paulo, 1999.

- "O Segredo de Luísa", de F. Dolabela; 6 ${ }^{\mathrm{a}}$ ed., Cultura Editores Associados: São Paulo, 1999.

- “Boa Idéia! E agora? Plano de Negócio, o caminho mais seguro para criar e gerenciar sua empresa" de F. Dolabela e L.J. Filion; Ed. Cultura: São Paulo, 2000.

- "Empreendedorismo: Transformando Idéias em Negócios" de José Carlos Assis Dornelas; Elsevier, 2001.
- "Tchau Patrão", de Eder Luiz Bolson; Ed. SENAC:MG, 2003.

- Curso SEBRAE gratuito por Internet chamado "Iniciando um Pequeno Grande Negócio".

\section{CONSIDERAÇÕES FINAIS}

A "Capitalização do Conhecimento" e o surgimento da "Universidade Empreendedora" são processos que já estão ocorrendo em todo o mundo, inclusive no Brasil de forma acentuada. Iniciativas como o ensino de emprendedorismo, proteção intelectual, licenciamento de patente e SOA farão parte do cotidiano das Universidades em um futuro próximo. As perguntas que sempre surgem são: Será que isso é realmente função da Universidade? Será que não irá degenerar o ensino e a pesquisa? Várias experiências, especialmente nos EUA e em alguns países Europeus, mostram que as Universidades mais empreendedoras estão sempre entre as melhores nos quesitos ensino e pesquisa, atraindo muitos financiamentos, os melhores pesquisadores e estudantes. Além disso, muitas publicações científicas e relatórios governamentais mostram de forma bastante clara o impacto que a utilização do conhecimento gerado nas Universidades pode ter na economia de uma região e de um país. Assim, esta mudança no modelo de Universidade ensino/pesquisa para Universidade ensino/pesquisa/empreendedorismo parece inevitável. A capacidade de se adaptar a estas mudanças, absorvendo, aprendendo e estimulando o empreendedorismo será fundamental na projeção das Universidades nas próximas décadas e trará muitos benefícios para o Brasil. No ambiente altamente competitivo e globalizado em que vivemos, a seleção natural de Darwin com o "survival of the fittest" é sempre citada: "tem mais chances de sobreviver não o mais forte mas o mais apto, aquele que tem melhor capacidade de adaptação".

\section{AGRADECIMENTOS}

A E. Santos e G. Junqueira do Instituto Inovação pelas valiosas sugestões para o trabalho. R. M. Lago agradece ao CNPq e HEC pelo estágio sabático e disponibilização de todos os recursos para a realização deste trabalho. À Dolabela e seu livro "O Segredo de Luiza" que inspiraram a forma deste artigo.

\section{REFERÊNCIAS}

1. Shane, S.; Academic Entrepreneurship. University Spin-offs and Wealth Creation, Edward Elgar, Northampton: EUA, 2004.

2. www.oecd.org, acessada em Agosto 2005.

3. Pirnay, F.; Surlemont, B.; Nlemvo, F. ; Small Bus. Econ. 2003, 21, 355.

4. Rappert, B.; Webster, A.; Charles, D.; Res. Pol. 1999, 28, 873.

5. Hindle, K. ; Yencken, J.; Technovation 2004, 24, 793.

6. Carayannis, E. G.; Evans, D.; Hanson, M.; Technovation 2003, 23, 757.

7. Araújo, M. H.; Oliveira, L. C. A.; Cabral, P. R. M.; Filion, L. J.; Cheng, L. C.; Lago, R. M.; Quim. Nova 2005, 28 Suplemento, S18.

8. Cohen, W.; Taking Care of Business, ASEE Prism Onlin 2000, p.1-5 (Association of University Technology Managers, www.autm.net acessada em Agosto 2005.

9. Goldman, M.; Technol. Rev. 1984, 86, 6

10. Mustar, P.; Sci. Pub. Pol. 1997, 24, 37.

11. Wickstead, S.; The Cambridge Phenomenon, Thetford Press: Thetford, 1985.

12. Dahlstrand, A.; Regional Studies 1999, 33, 379.

13. Lowe, R.; Tese de Doutorado, Universidade da Califórnia, Estados Unidos, 2002.

14. Wilson, M.; Szygenda, S. Em University Spin-off Companies; Brett, A.; Gibson, D.; Smilor, R., eds.; Rowman Littlefield Pub, Lenham: Sweden, 1991.

15. Zucker, L.; Darby, M.; Armstrong, J.; Econ. Inquiry 1998, 36, 65.

16. Pressman, L.; AUTM Licensing Survey 2001, Association of University Technology Managers, Northbrook, 2002. 
17. Tornatzky, L. G.; Waugaman, P.; Gray, D. O.; Innovation U.: New University Roles in a Knowledge Economy, Southern Growth Policies Board: North Caroline, 2002.

18. Dados compilados da ref. 1, que cita diferentes referências.

19. Pressman, L.; Guterman, S.; Abrams, S.; Geist, D.; Nelsen, L.; J. Assoc Univ. Technol. Manag. 1995, 7, 49.

20. Thursby, J.; Jensen, R.; Thursby, M.; J. Technol. Transfer 2001, 26, 59.

21. Kenney, M.; Biotechnology: The University-Industrial Complex, Yale University Press: New Haven, 1986.

22. Louis, K.; Jones, L.; Anderson, M.; Blumenthal, D.; Campbell, E.; J. Technol. Transfer 2001, 12, 435.

23. Filion, L. J.; Revista de Administração de Empresas FGV 1999, 39, 6; Filion, L. J.; RAUSP Revista de Administração 1999, 34, 5.
24. Paula, R. A. S. R.; Cheng, L. C., Anais do XV Seminário Nacional de Parques Tecnológicos e Incubadoras de Empresas, Curitiba, Brasil, 2005.

25. Cheng, L. C.; Drummond, P.; Mattos, Anais do XV Seminário Nacional de Parques Tecnológicos e Incubadoras de Empresas, Curitiba, Brasil, 2005.

26. Phaal, R.; Farrukh, C.; Probert, D.; T-Plan: Fast Start to Technology Roadmapping, Cambridge University Press:Cambridge, 2001.

27. Marxt, C.; Hacklin, F.; Rothlisberger, C.; Schaffner, T.; Proceedings of the IEEE International Engineering Management Conference, Singapore, 2004.

28. Etzkowitz, H.; Social Problems 1989, 36, 14

29. Ndonzuau, F. N.; Pirnay, F.; Surlemont, B.; Technovation 2002, 22, 281.

30. Carayannis, E. G.; Rogers, E. M.; Kurihara, K.; Allbritton, M. M.; Technovation 1998, 8,1 . 